\title{
Factorial structure analysis of the Torrance Test with Portuguese students
}

\author{
Análise da estrutura fatorial dos Testes de \\ Torrance em estudantes portugueses
}

\author{
Ricardo PRIMI' \\ Tatiana de Cássia NAKANO² \\ Maria de Fátima MORAIS ${ }^{3}$ \\ Leandro Silva ALMEIDA ${ }^{4}$ \\ Ana Paula Marques DAVID
}

\begin{abstract}
In order to verify the factorial structures of the Torrance verbal and figural tests, two activities of each instrument were applied with 193 students from the $10^{\text {th }}$ and $12^{\text {th }}$ years of education in Portugal. We tried to demonstrate that the collinearity of the fluency and flexibility variables could create methodological artifacts that hinder the understanding of the internal structure underlying the test. The principal component analysis without control of collinearity indicated a solution composed of four basic factors that separeted activities. Controlling for collinearity, we found a new solution, which also contained four factors that, unlike the previous result, grouped variables with similar processes but of different activities. The verbal and figural content is also an important element in the factor structure. This new arrangement makes more sense with the theory that underlies the instruments separating the different processes and content which are being measured by the activities.
\end{abstract}

Uniterms: Creativity measurement; Factor analysis; Test validity; Torrance tests.

\section{Resumo}

Com a finalidade de verificar a estrutura fatorial dos testes de Torrance, duas atividades verbais e duas figurais foram aplicadas em 193 estudantes do $10^{\circ}$ e $12^{\circ}$ ano do ensino secundário de Portugal. Tentou-se demonstrar que a colinearidade das variáveis fluência eflexibilidade podem criar artefatos metodológicos que dificultam o entendimento da estrutura interna subjacente ao teste. A análise fatorial dos componentes principais, sem controle da colinearidade, indicou uma solução composta por quatro fatores que separam basicamente as atividades. Controlando-se a colinearidade, encontrou-se uma nova solução, também composta por quatro fatores, que, diferentemente da anterior, organizou variáveis com processos semelhantes, mas de diferentes atividades. O tipo de conteúdo, verbal e figural, mostrou-se ainda um importante elemento na organização dos fatores. Esse novo arranjo fez mais sentido diante da teoria que embasa os instrumentos, ao separar os diferentes processos e conteúdos por eles avaliados.

Unitermos: Medidas de criatividade; Análise fatorial; Validade do teste; Teste de Torrance.

\section{$\boldsymbol{\nabla \nabla \nabla \nabla}$}

1 Universidade São Francisco, Laboratório de Avaliação Psicológica e Educacional, Programa de Estudos Pós-Graduados em Psicologia. R. Alexandre Rodrigues Barbosa, 45, 13251-900, Itatiba, SP, Brasil. Correspondence to/Correspondência para: R. PRIMI. E-mail: <rprimi@mac.com>.

2 Pontifícia Universidade Católica de Campinas, Centro de Ciências da Vida, Programa de Pós-Graduação em Psicologia. Campinas, SP, Brasil.

3 Universidade do Minho, Instituto de Educação. Braga, Portugal.

4 Universidade Católica Portuguesa, Instituto de Psicologia. Braga, Portugal.

Article developed as part of the dissertation data A.P.M. DAVID, called "Competências criativas no ensino secundário: um estudo em diferentes anos de escolaridade areas acadêmicas". Universidade Católica Portuguesa, 2008. Support: Conselho Nacional de Desenvolvimento Científico e Tecnológico. 
Based on the assumption that divergent thinking is a principal component of creative achievement (Cropley, 2009; Guilford, 1956), the best known and most widely used tests for creativity assessment are the Torrance Tests of Creative Thinking (De la Torre \&Violant, 2006; Torrance, 2000). Developed by Torrance (1966; 1990; 1998), the instruments include written and drawn answers, subject scores for each creative characteristic assessed, or cumulative results that are combined into a single creativity score for each individual. These instruments have several merits, including the diversity and quantity of information they provide, both for education and for research; the fact that they are both easy and quick to administer (Swartz, 1988); and that they have been applied and analyzed more than any other instrument for assessing creativity (Johnson \& Fishkin, 1999; Millar, 2002). Furthermore, they have the advantage of a relevant longitudinal validation (Davis, 1998), and predict success with regard to the quantity and quality of the creative output (Torrance, 1969, 1972, 1980, 1999; Wechsler, 2006).

Due to the popularity of the Torrance model for assessing the creativity and diversity of the creative characteristics evaluated in its tests, many researchers interested in investigating the psychometric properties of these instruments have developed studies in order to identify their factorial structures. These studies have aimed to answer one of the main issues raised in relation to the instruments in question: what is the factorial structure underlying the characteristics they evaluate? A literature review indicated two types of studies, those of exploratory factorial analysis and those of confirmatory factorial analysis, as noted below.

The first exploratory study of the factorial structure of the Torrance figural and verbal tests to be cited was made by Plass, J.J. Michael and W.B. Michael (1974) with 111 sixth grade children. In the model used, both instruments evaluated the characteristics of fluency, flexibility, elaboration and originality, in seven activities, totaling 30 measurements. Factor analysis with varimax rotation was used to verify how many uncorrelated latent dimensions were needed to explain the correlations between variables. The results indicated the existence of seven factors that separated the activities and the type of creativity (verbal or figural).

20 Factors 1, 3, 4, 5 and 6 separated the verbal activities
(Asking and Guessing Consequences in factor 1, Guessing Causes in factor 3, Unusual Uses in factor 4, Just Suppose in factor 5, and Product Improvement in factor 6), while factors 2 and 7 separated the figurative activities (Lines and Picture Completion, respectively).

A second study, of only the factorial structure of the figural tests, was developed by Clapham (1998), considering the fact that a single general factor appeared to be insufficient to express the divergent thinking ability. Thus, a study was conducted with the aim of investigating the structure of the figural Torrance tests (types A and B), with 344 psychology students between 17 and 45 years of age (with a mean age of 19 years). The results of the principal component analysis showed that, contrary to the author's expectation, the characteristics obtained in forms A and B did reflected a single general factor of creativity (composed by the characteristics of creative fluency, originality, title abstraction, elaboration, and resistance to premature closure), which would explain $55.89 \%$ and $50.27 \%$ of the variance, respectively, indicating that the structure of the two forms would still be equivalent. Note that in this study, the characteristics and activities were not investigated separately, only the total score for each test.

Investigating form A of the figural Torrance Test, Heausler and Thompson (1988), in turn, used the instrument with 132 students (69 in kindergarten and 63 in the second grade, with a mean age of 6.4 years), evaluating five criteria (originality, elaboration, resistance to premature closure, fluency and title abstraction). The authors found, after varimax rotation, a matrix composed of two factors. The first reflected a general creative factor, which was composed of the characteristics of originality, elaboration, resistance to premature closure, and fluency, while the second was composed of only title abstraction. It should be highlighted, however, that in this type of study, a significant loss of information can be noted due to the fact that the creative characteristics are not evaluated separately in each activity, ignoring the processes that are differentiated according to what is required for each task.

Accordingly, Antunes (2008), following the high correlations obtained between the creative characteristics assessed by the Torrance Tests (figural and verbal - form A version Wechsler, 2002), a question 
was raised regarding the appropriateness of creative parameters being in isolation, assuming a unique value, resulting from the sum of various subtests, or considering the results of those parameters separately for each subtest. In order to address the question, two analyses were performed with a sample population from Portugal. An initial exploratory factorial analysis considered each parameter in each activity separately, the results of which indicated a solution composed of five factors (activity 3 figural, activity 5 verbal, activity 2 figural, activity 4 verbal, and a last factor that grouped three measures of elaboration), confirming the "hypothesis of grouping by subtest and not by creative parameters, since only elaboration seems to emerge in factor 5, associated with three of the four tasks used" (Antunes, 2008, p.112). A second analysis, considering the parameters in a single measure, no longer separated by activity, indicated, in the exploratory factorial analysis, a two factor solution: the first factor associated with the figurative content (which explained $42.99 \%$ of the variance), and a second factor associated with the verbal content (explaining $18.56 \%$ of the variance), again indicating the separation by type of activity and not by the creative process.

Factorial analysis was also used by Oliveira, Conde, Pessoa, Batista and Fernandes (2006), from the Torrance results of three verbal subtests and three figural subtests with 697 students in the second cycle of elementary education in Portugal. The characteristics evaluated in each activity were considered, yielding a solution composed of six factors that explained $77 \%$ of the variance and that separated the activities (activity 3 figural, activity 2 verbal, activity 3 verbal, activity 1 verbal, activity 2 figural, and a fifth factor comprised of the three elaboration measures). The results basically permitted, "[one] to conclude that subjects tend to manifest a performance in the Torrance tests as a function of the type of evidence in question. Only elaboration emerges as the sole factor that brings together the same criteria in different tests" (Oliveira et al., 2006, p.365).

Based on exploratory factorial analysis, Azevedo (2007) examined the results of 348 students of Elementary and Secondary Education in Portugal (pre-adolescents and adolescents), in a version of the figural instrument translated and adapted to its Portuguese context by the author. Two factors emerged in this study: the first consisting of the parameters of fluency, originality, and resistance to premature closure (explaining $42.82 \%$ of the variance), and the second grouping the characteristics of creative force, title abstraction and elaboration (explaining $26.15 \%$ of the variance).

To analyze the construct validity of these tests, Almeida, Prieto, Ferrando, Oliveira and Ferrándiz (2008), reported the results of three studies conducted with samples from Spain and Portugal. In the first study, performed with 649 children between age 5 and 12, three activities of the figurative instrument were employed, from the version adapted to the Spanish language In the second study, with 595 pre-adolescents between 10 and 14 years, a version translated directly from the original instructions to Portuguese was used, applying six activities (three figural and three verbal). In the third study 310 pre-adolescents, between 10 and 15 years of age, were evaluated, using two verbal tasks and two figurative tasks from Wechsler's version (2002). The results were evaluated in relation to the characteristics of fluency, flexibility, elaboration, and originality, and their occurrence in each activity. In all the studies the results of the exploratory factor analysis indicated solutions that did not separate the cognitive processes, however, did separate the tasks, so that, according to the authors, the content of each task is shown to be more decisive for the performance of the student than the cognitive processes used to define and measure creativity.

Similarly, investigations involving confirmatory factor analysis can also be found in the literature; for example, the study of Kim, Cramond and Bandalos (2006), with 3,000 students (kindergarten, third, and sixth grades), which, using the figural test form $A$, tested a singlefactor model and a two-factor model. The results showed much better levels of adjustment in the two-factor model, in which the first factor was named Innovative, composed of the characteristics fluency, originality, and resistance to premature closure; and a second factor, named Adaptive, composed of elaboration, title abstraction, and resistance to premature closure. Once again, the group of variables was presented according to the type of creative parameter.

Furthermore, using confirmatory factor analysis and confirming previous data, Kim (2006) investigated whether the creative parameters evaluated in the figural Torrance Test form A (fluency, originality, resistance to 
premature closure, elaboration, and title abstraction) would behave as one or two factors. This study was conducted with 500 students in the sixth grade and the author highlighted that the two-factor model provided better results than the single-factor model. The two factors were found to be consistent with Kirton's (1994) description of the adaptation-innovation theory, as the first factor was composed of the characteristics fluency, originality, and resistance to premature closure, while the second factor was formed by elaboration, title abstraction, and resistance to premature closure. Again, it should be noted that the parameters were evaluated in their entirety, not considering their occurrence in each activity.

From the use of various creativity measures, Clapham (2004) developed a study with 285 Psychology students of a private university, using two creativity inventories (How doyou think? and How Creative areyou?), and the figural and verbal Torrance Tests. The first inventory assesses areas including energy level, originality, interests, activities, self-confidence, sense of humor, flexibility, willingness to take risks, and playfulness. The second inventory is divided into nine subscales: attitudes toward work, problem-solving behavior, interests, childhood-adolescence, value orientations, interpersonal relationships, personality dimensions, self-awareness checklist and negative selfimage. In turn, the verbal Torrance test was corrected in relation to the characteristics of fluency, flexibility, and originality, and the figural instrument relative to fluency, originality, title abstraction, elaboration, and resistance to premature closure. Factor analysis through the principal component method was then carried out to evaluate the relationship between the results of the different creativity tests and indicated the existence of three factors that explained $50.78 \%$ of the total variance. The factors were distinguished according to test type, so that the first factor was called Interests and Attitudes, and grouped the scores of the two inventories; the second factor was called Divergent Verbal Thinking and grouped the characteristics evaluated in the verbal Torrance Test; and the third factor, called Divergent Figural Thinking, grouped the characteristics evaluated in the figural Torrance Test. The results showed a distinction of divergent thinking tests only according to the type of activity (verbal, figural and inventory of attitudes/interests), rather than a single factor of 22 divergent thinking.
Belcher, Rubovits and Di Meo (1981), using factor analysis on the results of 108 university students who responded to ten creativity measures, found five factors. The first factor corresponded to three measures of personality and two verbal tests of idea association, being interpreted as a measurement of the convergent thinking process. Three other factors consisted, each separately, of a task/activity of the Torrance instruments (figural test Circles, verbal test Just Suppose, and verbal test Unusual (Uses), being interpreted as a measure of the divergent thinking process. The final factor consisted of two interest inventories: What Kind of Person areyou? and How do you think? According to the authors, the results suggested the existence of low convergent validity between the results of different types of creativity tests. The data again showed a grouping of measures by activity type.

Thus, we can see that since the early studies conducted on creativity by Guilford (1960), proposing a multidimensional model (Chen \& Michael, 1993, Torrance, 1966), many researchers have suggested several independent factors in this construct (Kim et al., 2006). The brief literature review presented in this paper shows the diversity of results: with factors that group the parameters according to the creative activities of the tests (Antunes, 2008; Belcher et al., 1981; Clapham, 2004; Oliveira et al., 2006; Plass et al., 1974); factors that combine creative parameters (Azevedo, 2007; Kim et al., 2006); studies that have considered the creative parameters globally, ignoring their occurrence in different activities (Kim, 2006); and studies that found a general factor of creativity (Clapham, 1998; Heausler \& Thompson, 1988). Given the diversity of results, a question remains regarding which creativity structure, in terms of number and organization of the factors, is suggested by the factorial analysis studies of the Torrance Tests.

Part of the variability of results concerning this issue can be attributed to methodological differences. Studies vary in the number and range of tests used, the use of exploratory or confirmatory factor analysis, and the use of different age ranges and sample sizes. However, a hypothesis that arises refers to the fact that one of the main reasons for the variations in the results can be related to the choice of variables and to the control of collinearity between them. 
This problem is particularly important when using factor analysis based on correlations between indicators to infer the presence of latent dimensions. The existence of strong collinearity between some variables can often be seen in tests of divergent thinking tasks, due to the way they are conceived and scored (especially regarding the characteristics of fluency, flexibility, and originality). In this context, some of them turn out to be relatively redundant, such as fluency and flexibility, with the former defined as the number of ideas presented by the subject to a given stimulus, and the latter, the number of different ideas. Both variables are based on a common observed indicator (number of ideas), given that, in one (fluency), the important thing is the total number of responses, while in the other (flexibility), the number of distinct ideas is valued. So we might think of an equation in which fluency $=$ the number of distinct ideas (flexibility) + number of repetitions. Thus, flexibility is implicated within fluency, depending on its definition, so as not to constitute two distinct indicators.

Chase (1985), for example, asserted that the correlation coefficients between fluency, flexibility, and originality are high (between 0.74 and 0.80 ), so that considering only one of the variables could be appropriate to represent the others. Confirming this finding, Antunes (2008) also reported high levels of correlation between fluency and flexibility ( 0.91 for the figurative test and 0.78 for verbal), given that, when analyzed separately (each parameter in each activity), the correlations were still high $(0.52$ for activity 4 and 0.89 for activity 5 of the verbal test; 0.92 for activity 2 and 0.84 for activity 3 of the figural test) in a sample of elementary school students. Other researchers, such as Chase (1985), Clapham (1998), Heausler and Thomson (1988), Morais and Azevedo (2009), and Runco and Mraz (1992) have also highlighted these problems.

According to the note by Heausler and Thomson (1988), since 1972, Thorndike has called attention to the lack of evidence of consistency in scoring measures of fluency, flexibility, and originality - it did not surprise him that the results of these parameters tend to be highly correlated. This problem can be understood by examining their definitions, from which it can be seen that the evaluation of fluency and flexibility appears to be somewhat redundant since, for there to be flexibility (diversity) there must necessarily be fluency (adequate responses), as pointed out previously, so that the hypothesis developed that flexibility would be somewhat more elaborate than fluency. However, there is the problem that part of this association appears to be related to how these indicators are defined, and not due to a common psychological process to be investigated. Given the fact that the variables are based on a single observable (analyzed in the same response), this fact is likely to result in a high correlation between them due to a methodological artifact, confirmed by the high correlations found in the scientific literature, a fact that will eventually confuse the covariance structure which is analyzed in search of the constructs. Therefore, part of the divergence of results may be related to the choice of variables (whether divided by activities or by parameters), and to whether a collinearity control is used.

Thus, this study aimed to identify the factorial structure of the verbal and figural Torrance Tests in a sample of Portuguese students, applying the control of collinearity to verify whether the results are different when considering the variables using this feature.

\section{Method}

\section{Participants}

We used a convenience sample composed of 193 students who attended the $10^{\text {th }}(n=114)$ and $12^{\text {th }}$ $(n=79)$ grades of schooling in Portugal, corresponding to high school education in Brazil. Of these students, 94 were from the Visual Arts course (64 females and 30 males) and 99 were from the Science and Technology course (53 females and 46 males).

\section{Instruments}

We used the verbal and figural instruments of the Torrance Creative Thinking Test, in order to evaluate four aspects of creative thinking: fluency (number of valid responses), flexibility (number of different categories of responses), elaboration (details in the composition of the response), and originality (statistical rarity of the responses, assigning zero to those responses given by $5 \%$ or more of the individuals whose tests were evaluated, one point to the answers given by between 
$2 \%$ and $4.99 \%$, and two points for the responses given by less than $1.99 \%$ of the subjects).

Oliveira's (1992) verbal version was used, adapted for the age group concerned and for Portugal. Activities 1 and 5 were selected from the test, in which the parameters evaluated were fluency, flexibility, and originality. The first activity (Ask Questions) allows students the freedom to pursue curiosity and develop hypotheses and assumptions. Starting from an enigmatic figure supposedly contemplating the water, students were asked to write all the questions they could think of, which could not be answered by mere observation of the figure, to explain what was happening. The number of valid questions provided an indication of fluency; the diversity of categories reflected flexibility; and the type of questions revealed originality. In activity 5 students were asked to think of unusual uses for cardboard boxes (Uncommon Uses). The instructions relate to the stimuli of fluency, flexibility, and originality.

Wechsler's (2002) figural version was used, adapted for the Portuguese language and the age group in question with Brazilian samples. Activities 2 and 3 were selected from the test, in which the parameters fluency, flexibility, and elaboration are evaluated. In activity 2 (Figure Completion), the students were asked to make use of ten incomplete figures to create a picture or object, to which they should assign a title at the end. The instructions encourage the use of the creative skills assessed: fluency, flexibility, and elaboration. In activity 3 (Lines), the students were asked to create drawings from 30 pairs of parallel lines. Again, the instructions sought to encourage fluency, flexibility and elaboration.

\section{Procedure}

The application of the instruments occurred collectively in the classroom, with a few minutes interval between tests (first the figural test was applied and then the verbal test).

The tests were graded for the characteristics of fluency, flexibility, elaboration, and originality, with calculation of means, standard deviations, and the minimum and maximum score in each activity and each test (verbal and figural). As noted, it can be seen that the fluency and flexibility variables were highly collinear. The correlations between these variables in the present study occurred as much in relation to the figural instrument ( $r=0.80$ in activity 2 and $r=0.84$ in activity $3, p \leq 0.01$ ), as in relation to the verbal instrument $(r=0.84$ in Activity 1 and $r=0.87$ in Activity 5, pd"0.01), indicating a high redundancy between what is assessed by the two parameters, as explained in the introduction. Thus, in this type of study some statistical control needs to be performed before submitting the matrices to factorial analysis. Therefore, the factor analyses were performed twice, once without the control and then with the redundancy control. The working hypothesis was that we would have different structures depending on the type of variable used, a fact that could explain the differences between the results of the factorial structure of the Torrance tests found in the literature.

Accordingly, the solution proposed as a means of controlling such redundancy is the use of linear regression with the aim of predicting fluency from flexibility. This procedure allowed the calculation of the standardized residuals, called residual fluency, which represents the portion of fluency not associated with flexibility (namely, that composed of repetitions and/or productivity of ideas in the same categories). Thus, the factor analysis with redundancy control, rather than considering the result in fluency, opts to consider these residuals. This is because, as already seen, the simple insertion of the fluency, rather than the residual fluency, causes the same component to be considered in duplicate (as fluency is defined as the number of different ideas + number of repetitions, and flexibility as the number of different ideas), artificially increasing the correlations by activity. However, when considering only the residual fluency, we have two distinct and separated components, i.e., different ideas and repetitions.

At the same time, another methodological control is performed which refers to the separation of the parameters by activity, in order to make the variables (fluency, flexibility, originality and elaboration) truly different (in different tasks: figural 2, figural 3, verbal 1, and verbal 5). Thus this selection of variables was intended to better clarify the factorial structure of the psychological processes that are supposed to be underlying the variables. Interestingly, most of the studies in the literature performed the analysis of the variables in general, rather than dividing them by activity, and did not control the linear dependence of some variables. 


\section{Results and Discussion}

Considering that the aim of this study was to investigate the internal structure of the variables assessed by the verbal and figural Torrance Tests $(1966 ; 1998)$ in order to better understand the constructs that these variables represent, two different analyses were performed, one without the control of collinearity between the characteristics of fluency and flexibility, and the other controlling this collinearity through the use of residual fluency. Initially, we proceeded to check the adequacy of the correlation matrix for factorial analysis, verifying the adequacy of the data to conduct this type of analysis, by way of Bartlett's sphericity test, which showed a highly significant result $\left(\chi^{2}=1736.031\right.$; $N=193 ; p \leq 0.001)$. The analysis of the sample adequacy using the KMO method (Kaiser-Meyer-Olkim) was also performed and resulted in a value (0.71) that verified the adequacy of the data to perform the analysis.

Therefore, the realization of the first exploratory factor analysis, without control of collinearity, by the principal components method with oblimin rotation, indicated four factors that had eigenvalues greater than one, confirmed by the scree plot analysis. The eigenvalues were, respectively, 2.98, 1.62, 1.47 and 1.34, which would explain $37.12 \%, 18.80 \%, 14.11 \%$ and $11.65 \%$, that is, $81.69 \%$ of the total variance. Table 1 shows the extracted factors, their contents, the factor loadings, and descriptive statistics for each of the parameters (minimum score, maximum score, mean and standard deviation) (Table 1).
As expected, the results showed that the separation of factor occurred in accordance with the activities of the instruments. It can be seen that the parameters evaluated in activity 1 of the verbal test (originality, flexibility and fluency) were grouped in the first factor. In factor 2, there was a grouping of the parameters fluency and flexibility of the figural instrument. The parameters evaluated in activity 5 of the verbal test (fluency, originality and flexibility) were grouped in factor 3. Finally, the fourth factor was comprised of the figurative elaboration characteristics (in activities 2 and 3). Thus, we see that three factors group characteristics by activity type (factors 1, 2 and 3), while only the last factor grouped characteristics related to the elaboration process (factor 4).

The presence of groupings by activity and content (verbal and figural) corroborates the data in the literature. Groupings by creative activity when analyzing separate results were also reported by Almeida et al. (2008), Belcher et al. (1981), Clapham (2004) and Plass et al. (1974). Thus, it was verified that without controlling the collinearity between fluency and flexibility, the shared portion of the variance between these variables that occurs within an activity causes a cluster of factors by activity/task type. Based on this observation, a second factorial analysis was performed controlling the collinearity of the variables through the residuals with the expectation of generating a more appropriate matrix to try to highlight the latent structure of the psychological factors connected to the creative processes.

Table 1

Descriptive statistics and matrix of factor loadings from the factor analysis without control of collinearity between fluency and flexibility

\begin{tabular}{|c|c|c|c|c|c|c|c|c|}
\hline Variable & F1 & F2 & F3 & $\mathrm{F} 4$ & Minimum & Maximum & Mean & SD \\
\hline Vrb ORIG1 & 0.947 & & & & 0 & 28 & 8.20 & 5.93 \\
\hline Vrb FLEX1 & 0.940 & & & & 0 & 13 & 5.40 & 2.37 \\
\hline Vrb FLU1 & 0.930 & & & & 0 & 29 & 10.01 & 5.37 \\
\hline Fig FLEX2 & & 0.906 & & & 1 & 11 & 5.56 & 2.18 \\
\hline Fig FLU2 & & 0.894 & & & 1 & 10 & 6.51 & 2.52 \\
\hline Fig FLU3 & & 0.756 & & & 0 & 30 & 11.36 & 5.99 \\
\hline Fig FLEX3 & & 0.735 & & & 0 & 25 & 8.77 & 4.36 \\
\hline Vrb FLU5 & & & 0.970 & & 1 & 49 & 17.17 & 9.37 \\
\hline Vrb ORIG5 & & & 0.949 & & 0 & 40 & 11.63 & 7.82 \\
\hline Vrb FLEX5 & & & 0.920 & & 1 & 21 & 10.24 & 3.97 \\
\hline Fig ELAB3 & & & & 0.873 & 0 & 43 & 8.40 & 7.37 \\
\hline Fig ELAB2 & & & & 0.846 & 0 & 43 & 10.23 & 7.64 \\
\hline
\end{tabular}

Note: Vrb: Verbal Test; Fig: Figural Test; ORIG: Originality; FLEX: Flexibility; FLU: Fluency; ELAB: Elaboration; SD: Standard Deviation. Final numbers refer to activities 1,2,3 and 5 . 
Verification of the adequacy of the correlation matrix for factor analysis was again performed, using the Bartlett's sphericity test, and showed a highly significant result $\left(\chi^{2}=838.350 ; N=193 ; p \leq 0.001\right)$. The adequacy analysis of the sample using the KMO method (Kaiser-Meyer-Olkim) was also performed, and resulted in a value $(0.45)$ close to that which is considered adequate (0.50).

This second factorial analysis was conducted using the principal components method with oblimin rotation and indicated the existence of four factors with eigenvalues greater than 1, confirmed by the analysis of the scree plot, which explained $61.93 \%$ of the total variance. The factors presented eigenvalues of $2.98,1.62$, 1.47 and 1.34 , corresponding respectively to $24.87 \%$, $13.54 \%, 12.30 \%$ and $11.20 \%$ of the variance. Table 2 shows the extracted factors, their contents and factor loadings.

The interpretation of the Table shows that, when controlling the fluency and flexibility, the factor analysis gives rise to factors that combine creative parameters, rather than activity, as was found in the previous analysis. This organization is related more to the psychological processes underlying each parameter. The first factor groups the parameters of flexibility and originality in the two verbal test activities. Factor 2 groups the parameter of elaboration in the two activities of the figural test. Factor 3 separates all fluency scores (in the two verbal activities and in the two figural activities), and Factor 4 groups the parameter of figural flexibility

\section{Table 2}

Factor loadings from the factor analysis controlling for collinearity between fluency and flexibility

\begin{tabular}{lcccc}
\hline Variable & F1 & F2 & F3 & F4 \\
\hline vrbFLEX1 & 0.937 & & & \\
vrbORIG1 & 0.865 & & & \\
vrbFLEX5 & 0.468 & & & \\
figELAB2 & & 0.829 & & \\
figELAB3 & & 0.804 & & \\
figFLU3rsd & & & 0.778 & \\
vrbFLU1rsd & & & 0.573 & \\
vrbFLU5rsd & & & 0.508 & \\
vrbORIG5 & 0.507 & & & \\
figFLU2rsd & & & 0.426 & \\
figFLEX2 & & & & 0.827 \\
figFLEX3 & & & & 0.715 \\
\hline
\end{tabular}

Note: Vrb: Verbal Test; Fig: Figural Test; ORIG: Originality; FLEX: Flexibility; FLU: Fluency, ELAB: Elaboration. Final numbers refer to activities 1,2, 3 and 5 . in activities 2 and 3. As expected, when controlling for collinearity, the analysis of such data gives rise to a different organization of factors, no longer by activity, but by the processes underlying the organized activities, such as those processes more connected to the production of diverse and unique ideas (factors 1 and 4), to the enrichment of ideas (factor 2) and to the production of various ideas on a similar theme (factor 3 ). It seems to be evident also that the activities are associated with verbal (factors 1 and 3) or figural (factors 2 and 4) content.

A study with the same purpose, developed by Nakano and Primi (2012) also indicated the existence of four separate factors as creative parameters for the results of the Children's Test of Figural Creativity, similar to the Torrance figural test. The factors constituted Idea Enrichment, which was composed of the elaboration characteristics in activities 1,2 and 3; using context in activities 2 and 3 ; internal perspective in activities 2 and 3; unusual perspective in activities 1,2 and 3; and movement in activities 2 and 3 . The second factor, called Emotionality was comprised by the characteristics of emotional expression in activities 2 and 3; expressive titles in activities 1, 2 and 3; and fantasy in activities 2 and 3. The third factor, called Cognitive Aspects, was composed of the residual fluency characteristics in activities 2 and 3; flexibility in activities 2 and 3; originality in activities 2 and 3; and extension of limits in activity 3. The fourth factor, called Creative Preparation, basically separates some characteristics evaluated in the first activity test (elaboration, originality, use of context, movement, and internal perspective) constituted by only one design, with the fact that the score range is restricted being due to the impossibility of scoring fluency and flexibility. The cited study also found grouping by creative parameters when controlling collinearity.

\section{Conclusion}

In this study, we attempted to demonstrate that the choice of variables for factor analysis can create methodological artifacts that complicate and confuse the understanding of the underlying internal structure of the Torrance tests. It was argued that the central point refers to the collinearity between the variables fluency and flexibility. The first factorial analysis performed in 
this study reproduced the results of studies that have adopted the same methodology, that is, with no control of collinearity, this analysis verified that variables tend to group by activity - a result similar to the reviewed studies. However, when the data were re-analyzed, eliminating the collinearity, a different result emerged, indicating a more coherent organization, with the creative processes and content assessed by task.

Therefore, attention should be given to how the studies on the factorial structure of the Torrance tests have been conducted. Some studies performed a factorial analysis with the overall results (of flexibility, fluency, elaboration and originality in different tasks), combined in a comprehensive way, while others worked with the scores of the variables in each activity. It is understood that the second method has been shown to be more appropriate because it produces multiple observations of the creative behavior manifestations of the same processes, increasing the observation of indicators reportedly connected to a common construct.

However, even in this second model, this study highlights the importance of controlling the collinearity of the variables, removing pseudo-correlations that could possibly confuse the covariance structure among variables. Although some studies highlighted the high correlations between some characteristics (mainly between fluency and flexibility), they did not test to what extent this collinearity affects the factorial structure, as was done in this study. It is interesting to note, then, that as hypothesized, when controlling this collinearity, the factors are not defined by variables of a single task (activity) as was found by. The four factor solution, found here, is different from the single-factor or two-factor models that have been reported in most studies found in the literature, which can be explained following the methodological adjustments that were made with the purpose of producing the most appropriate matrix of indicators for factor analysis. Furthermore, this analysis corroborates the existence of a factor connected to the production of diverse and original ideas, and another connected to enrichment and elaboration, which were also found in the literature. Another aspect refers to the content of the tasks in question, indicating that the factors are also organized by means of verbal or figural expression. In summary, the results suggest that the factorial solution that involves the control of collinearity between fluency and flexibility was shown to be more appropriate for the differentiation of the diverse creative processes assessed by the instruments.

New studies in the evaluation of all creative parameters, which make use of the instruments with all subtests (as opposed to only a portion, as used here), are recommended in order to verify that the factorial structure remains when considering the nine activities that comprise the verbal and figural instruments.

\section{References}

Almeida, L. S., Prieto, L. P., Ferrando, M., Oliveira, E., \& Ferrándiz, C. (2008). Torrance Test of Creative Thinking: The question of its construct validity. Thinking Skills and Creativity, 3(1), 53-58.

Antunes, A. M. P. (2008). O apoio psico-educativo a alunos com altas habilidades: um programa de enriquecimento numa escola inclusiva (Tese de doutorado não-publicada). Universidade do Minho, Portugal.

Azevedo, I. (2007). Criatividade e percurso escolar: um estudo emjovens do ensino básico e secundário (Tese de doutorado não-publicada). Universidade do Minho, Portugal.

Belcher, T. L., Rubovits, J. J., \& Di Meo, P. A. (1981). Measurement of creativity: A factor analytic study. Psychological Reports, $48,819-825$.

Chase, C. I. (1985). Review of the Torrance Tests of Creative Thinking. In J. V. Mitchell Jr. (Org.), The ninth mental measurements yearbook (pp.1631-1632). Lincoln: University of Nebraska Press.

Chen, S. A., \& Michael, W. B. (1993). First-order and higherorder factors of creative social intelligence within Guilford's structure of intellect model: A reanalysis of a Guilford data-base. Educational and Psychological Measurement, 53(3), 619-641.

Clapham, M. M. (1998). Structure of figural forms A and B of the Torrance Tests of Creative Thinking. Educational and Psychological Measurement, 58 (2), 275-283.

Clapham, M. M. (2004). The convergent validity of the Torrance Tests of Creative Thinking and creativity interest inventories. Educational and Psychological Measurement, 64(5), 828-841.

Cropley, A. (2009). Creativity in education and learning: A guide for teachers and educators. New York: Routledge.

Davis, G. A. (1998). Creativity is forever. Dubuque: Kendall/ Hunt.

De la Torre, S., \& Violant, V. (2006). Compreender y evaluar la creatividad. Malaga: Ediciones Algibe.

Guilford, J. P. (1956). The structure of intellect. Psychological Bulletin, 53(4), 267-293.

Guilford, J. P. (1960). The structure of the intellect model: Its use and implications. New York: McGraw-Hill. 
Heausler, N. L., \& Thompson, B. (1988). Structure of the Torrance Tests of Creative Thinking. Educational and Psychological Measurement, 48, 463-468.

Johnson, A., \& Fishkin, A. (1999). Assessment of cognitive and affective behaviours related to creativity. In A. Fishkin, B. Cramond \& P. Olszewski-Kubilius (Orgs.), Investigating creativity in youth: Research and methods (pp.265-306). New Jersey: Hampton.

Kim, K. H. (2006). Is creativity unidimensional or multidimensional? Analyses of the Torrance Tests of Creative Thinking. Creativity Research Journal, 18, 251-259.

Kim, K. H., Cramond, B., \& Bandalos, D. L. (2006). The latent structure and measurement invariance of scores on the Torrance Tests of Creative Thinking-Figural. Educational and Psychological Measurement, 66(3), 459-477.

Kirton, M. J. (1994). Adaptors and innovators: Styles of creativity and problem solving. London: Routledge.

Millar, G. (2002). The Torrance kids at mid-life. Westport: Ablex.

Morais, M. F., \& Azevedo, I. (2009). Avaliação da criatividade como um contexto delicado: revisão de metodologias e problemáticas. Avaliação Psicológica, 8(1), 1-15.

Nakano, T. C., \& Primi, R. (2012). Teste de criatividade figural infantil: estrutura fatorial. Psicologia: Teoria e Pesquisa, 28(3), 275-283.

Oliveira, M. (1992). A criatividade, o pensamento critico e o aproveitamento escolar em alunos de ciências (Dissertação de mestrado não-publicada). Faculdade de Ciênçias, Universidade de Lisboa, Portugal.

Oliveira, E. P., Conde, S., Pessoa, P. E., Batista, C. J., \& Fernandes, H. (2006). Testes de pensamento criativo de Torrance: contributos para a sua aferição. Anais da XI Conferência Internacional de Avaliação Psicológica: formas e contextos (pp.357-367). Braga: Psiquilíbrios.

Plass, H., Michael, J. J., \& Michael, W. B. (1974). The factorial validity of the Torrance Tests of Creative Thinking for a sample of 111 sixth-grade children. Educational and Psychological Measurement, 34(2), 413-414.

Runco, M. A., \& Mraz, W. (1992). Scoring divergent thinking tests using total ideational output and a creativity index. Educational and Psychological Measurement, 52, 213-221.
Swartz, J. (1988). Torrance Tests of Creative Thinking. In D. Keyser \& R. Sweetland (Orgs.), Test critique (Vol.7, pp.619-622). Kansas: Test Corporation of America.

Torrance. E. P. (1966). Torrance Tests of Creative Thinking. Lexington: Personnel Press.

Torrance, E. P. (1969). Prediction of adult creative achievement among high school seniors. Gifted Child Quaterly, 13(4), 223-252.

Torrance, E. P. (1972). Predictive validity of "bonus" scoring for combinations on repeated figure tests of creative thinking. Journal of Psychology: Interdisciplinary and Applied, 81(1), 167-171.

Torrance, E.P. (1980). Empirical validation of criterion-referenced indicators of creative hability through a longitudinal study. Creative Child and Adult Quaterly, 6(3), 136-140.

Torrance, E. P. (1990). Torrance Tests of Creative Thinking: manual for scoring and interpreting results. Benseville: Scholastic Testing Service.

Torrance, E. P. (1998). The Torrance Tests of Creative Thinking norms: technical manual figural (streamlined) forms A \& B. Benseville: Scholastic Testing Service.

Torrance, E. P. (1999). Forty years of watching creative ability and creative achievement. Newsletter of the Creative Division of the National Association for the Gifted Children, 10(1), 3-5.

Torrance, E. P. (2000). Research review for the Torrance Tests of Creative Thinking: Figural and verbalform A and B. Bensenville: Scholastic Testing Service.

Wechsler, S. M. (2002). Avaliação da criatividade por figuras e palavras: testes de Torrance - versão brasileira. Campinas: Lamp/Impressão Digital do Brasil.

Wechsler, S. M. (2006). Validity of the Torrance Tests of Creative thinking to the Brazilian culture. Creativity Research Journal, 18(1), 15-25.

Received on: 14/4/2011

Final version on: 18/6/2012

Approved on: 18/7/2012 